\title{
Long-Term Results of Mandibular Reconstruction with Autogenous Bone Grafts and Oral Implants
}

\author{
Brajpal Singh Tyagi* and Sushant Tyagi \\ Department of ENT, Head and Neck Surgery, Harsh ENT Hospital, India
}

Submission: August 17, 2017; Published: September 07, 2017

*Corresponding author: Brajpal Tyagi, Harsh ENT Hospital, C43, RDC, Raj Nagar, Ghaziabad - 201 002, Uttar Pradesh, India,

Email: brajpaltyagi@gmail.com

\begin{abstract}
The reconstruction of mandibular defects after tumor resection is a challenging problems faced by Head and neck oncosurgeons. The mandible bone is known to play an important role in upper and lower airway protection and supporting of the musculature of tongue and dentition, as well as the muscles of floor of mouth, thus permitting the various physiologic acts of mastication, articulation, deglutition, and respiration. It is also known to provide for the contour of the lower face. Any interruption of mandible therefore produces both cosmetic and functional deformity. Resection of the mandible results in its deviation toward the resected side due to the unopposed pull of remaining muscles of mastication and scar formation. There is also limitations in movements of the jaw. We present a case of squamous cell carcinoma of left RMT \& gingivo-buccal sulcus with mandibular bone invasion. He underwent hemimandibulectomy and ipsilateral radical neck dissection with postoperative radiotherapy in 2003. After 13 years of follow up he presented to us with complete resorption of the iliac crest graft with intact implant and no other symptomatic complaints. In review of literature regarding comparison of vascularized fibular flap and iliac crest flap for mandibular reconstruction it was found that functional and aesthetic results also showed that oral continence, social activities, and facial appearance rates of fibula flap are superior to iliac crest flap. The main complications of using iliac crest grafts are anaesthesia of the skin supplied by the lateral cutaneous nerve of the thigh, incisional hernias, and wound dehiscence in the thigh.
\end{abstract}

Keywords: Bone resorption; Iliac bone graft; Hemimandibulectomy

\section{Case Report}

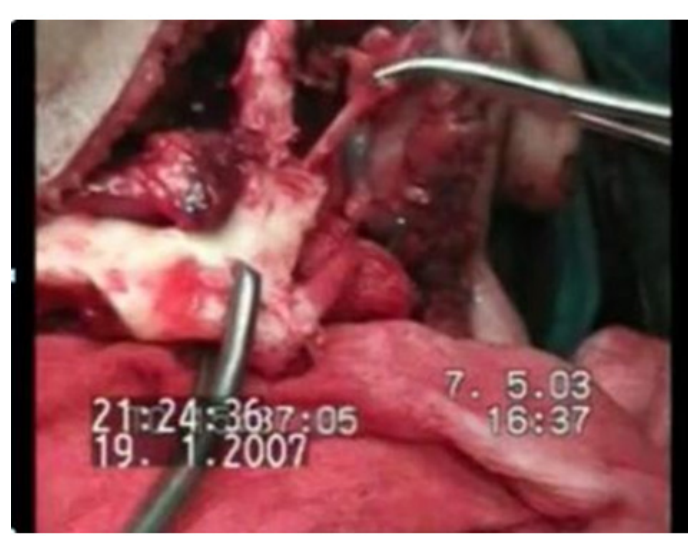

Figure 1: Intra operative hemimandibulectomy.

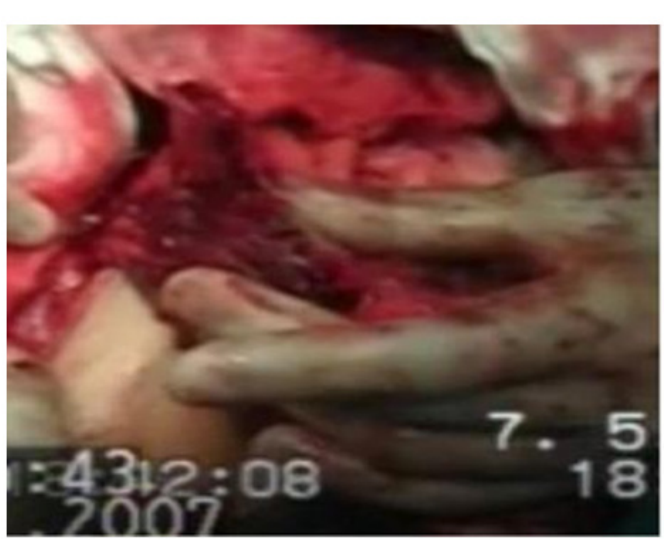

Figure 2: Iliac crest graft with vascular pedicle for anastomosis. 


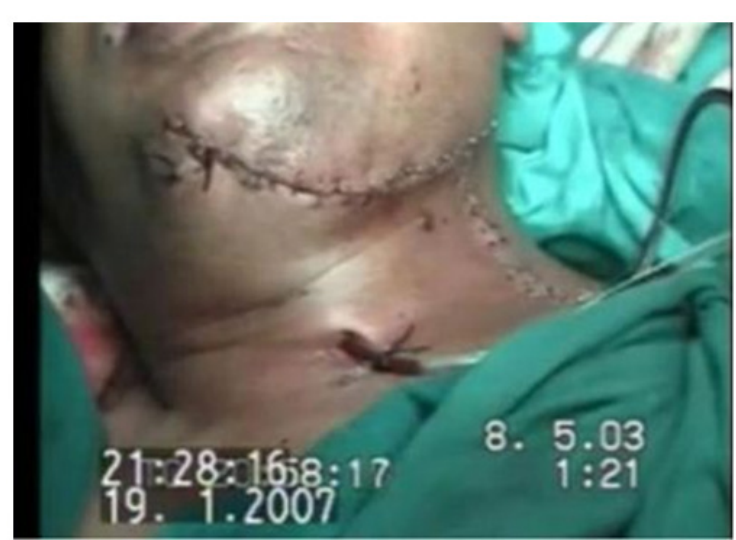

Figure 4: Post operative facial reconstruction (year 2003) venous anastomosis and reconstruction plates.

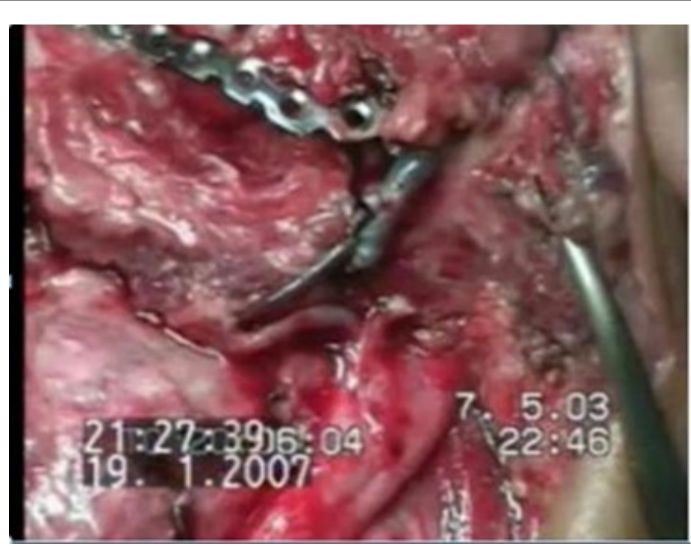

Figure 3: Facial artery and circumflex iliac artery.

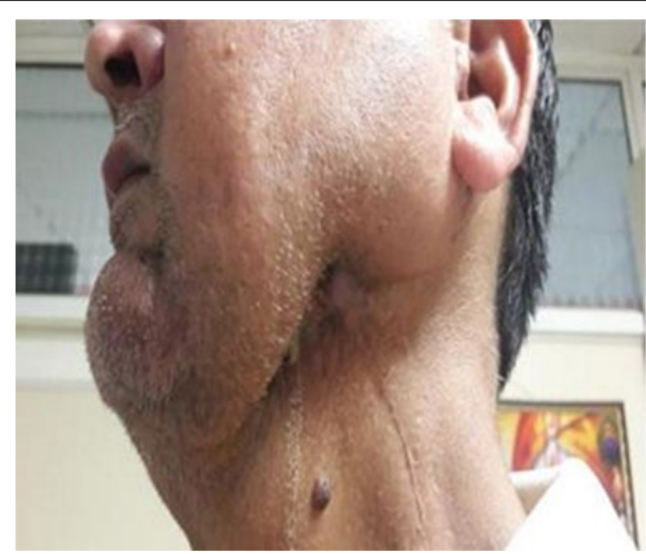

Figure 5: Post operative image after 13 years. (2016).

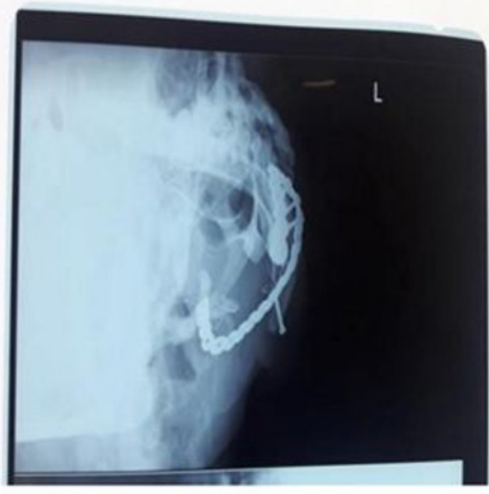

Figure 6: Post op radiograph showing complete resorption of iliac crest bone graft after 13 years.

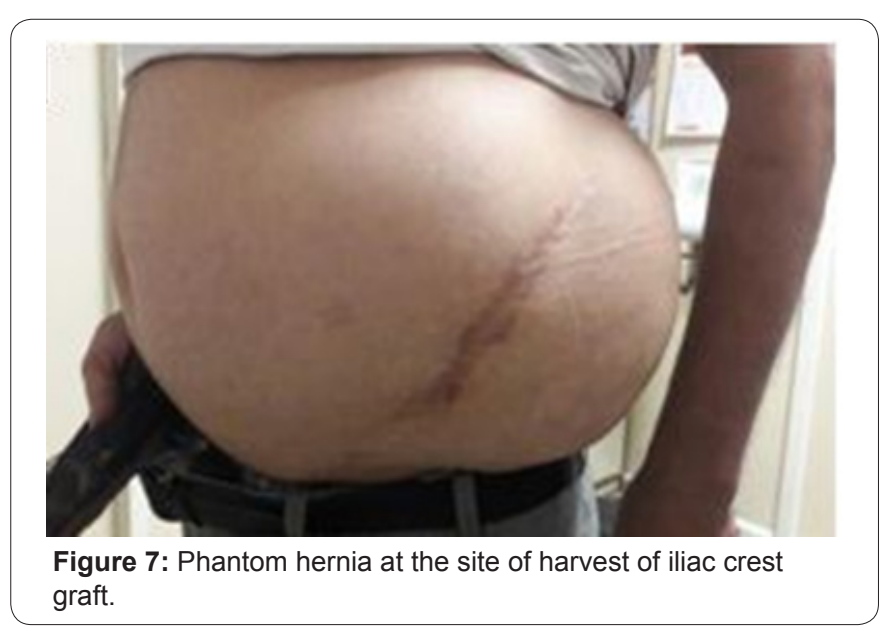

We present a case of squamous cell carcinoma (SCC) of the oral cavity with mandibular infiltration in a 35 years old male patient requiring hemimandibulectomy, treated by surgical resection, therapeutic neck dissection and radiotherapy. Grafts from the iliac crest were used for augmentation of the defect, however it was associated with complete bone resorption after 13 years of surgery as a possible late complication (Figure 1-7).

\section{Discussion}

The mandible is one of the important parts of the body in terms of facial appearance and function. Vascularized free bone grafts have become the criterion standard in mandible reconstruction. Bone grafts from the iliac crest showed a significantly higher bone loss of $24.16 \%$ [1].

Functional and aesthetic results also showed that oral continence, social activities, and facial appearance rates of fibula 
flap were superior to iliac crest flap. Lower complication rates of fibula flap group may be associated with patient's higher satisfaction rate. Both flaps are commonly used in mandibular

reconstruction; however, many parameters including defect localization, defect size, presence of soft tissue defect should be considered [2].

Fibular flap was the flap of choice in total/subtotal mandibulectomy, but it does not appear preferable in hemimandibulectomy and/or in cases of segmental mandibulectomy, if compared with the iliac crest [3]. Nonvascularized fibular bone graft is as better as iliac crest for reconstruction of mandibular defects of optimal length [4].

The main complications of using iliac crest grafts are anaesthesia of the skin supplied by the lateral cutaneous nerve of the thigh, incisional hernias, wound dehiscence in the thigh, oronasal fistulas, wound dehiscence in the neck, infection by methicillin resistant Staphylococcus aureus in the thigh, and long-term disturbances of gait [5].

The main advantages of reconstruction using fibular flap method include the bicortical structure of the bone and its adaptability to conform to the mandibular contour. The only real disadvantage is the limited height of the bone graft, which does not allow alveolar ridge reconstruction. An implant-borne dental prosthesis can, however, generally be made for functional occlusal rehabilitation [6].

Comparing the quality of life associated with these two methods of mandibular reconstruction Patients with an iliac crest bone graft had significantly better chewing and swallowing.
These findings suggest that reconstruction with the iliac crest had benefits in improved function (chewing, swallowing, and taste) rather than esthetics, donor site morbidity, or psychologic discomfort [7].

\section{Conclusion}

Both bone-grafting approaches are successful and reliable techniques, enabling implant placement in even highly atrophied alveolar ridges and with identical implant survival rates, although bone resorption differs.

\section{References}

1. Mertens C, Decker C, Seeberger R, Hoffmann J, Sander A, et al. (2013) Early bone resorption after vertical bone augmentation--a comparison of calvarial and iliac grafts. Clin Oral Implants Res 24(7): 820-825.

2. Yilmaz M, Vayvada H, Menderes A, Demirdover C, Kizilkaya A (2008) A comparison of vascularized fibular flap and iliac crest flap for mandibular reconstruction. J Craniofac Surg 19(1): 227-234.

3. Politi M, Toro C (2012) Iliac flap versus fibula flap in mandibular reconstruction. J Craniofac Surg 23(3): 774-779.

4. Agrawal A, Mehrotra D, Mohammad S, Singh RK, Kumar S, et al. (2012) Randomized control trial of non-vascularized fibular and iliac crest graft for mandibular reconstruction. J Oral Biol Craniofac Res 2(2): 9096.

5. Lyons AJ, James R, Collyer J (2005) Free vascularized iliac crest graft: an audit of 26 consecutive cases. Br j oral maxillofac surg 43(3): 210-214.

6. Reychler H, Ortabej IJ (1994) Mandibular reconstruction with the free fibula osteocutaneous flap. Int j oral maxillofac surg 23(4): 209-213.

7. Vu DD, Schmidt BL (2008) Quality of life evaluation for patients receiving vascularized versus nonvascularized bone graft reconstruction of segmental mandibular defects. J Oral Maxillofac Surg 66(9): 18561863.

\section{Your next submission with Juniper Publishers will reach you the below assets}

- Quality Editorial service

- Swift Peer Review

- Reprints availability

- E-prints Service

- Manuscript Podcast for convenient understanding

- Global attainment for your research

- Manuscript accessibility in different formats

( Pdf, E-pub, Full Text, Audio)

- Unceasing customer service

Track the below URL for one-step submission https://juniperpublishers.com/online-submission.php 